\title{
Tympanometric results from neonates and infants under four months
}

\author{
S. Varbanova \\ Medical University - Sofia, \\ ENT department - Audiology
}

\begin{abstract}
Advantages of objective studying the middle ear of infants and neonates are presented. High frequency timpanometry is proposed and used because of anatomical differences between children and adults. This method is used widely in diagnosing , because he is noninvasive, quick and easy to perform.
\end{abstract}

\section{Introduction}

The process of hearing begins with a simple interaction between the mechanical energy of the sound wave and the hearing analyzer. Clinical audiology uses different methods of testing and techniques for the accurate diagnosis of the hearing function. Acoustic impedancemetry gives us information about the functional capacity of the hearing analyzer and abnormalities in hearing.

In 1990, ASHA (American Speech-lanquage Hearing Association) recommends immittance testing to screen middle- ear diseases. Silverman and Arick (1992) create an immittance protocol for the early detection of otitis media with effusion in children. Katz (1994) defines this method as a routine, objective and sensitive for determining pathologies in the middle ear.

Significant hearing loss is one of the most common major abnormalities present at bird and, if undetected, will impede speech, language and cognitive development.

The hearing screening should detect all infants with significant bilateral hearing impairment, i.e. those with hearing loss $\geq 35$ decibel in the better ear.

Conductive hearing impairment are interruption of sound transmission due to absence, malformation or dysfunction of the outer ear, ear canal, ear drum or ossicles of the middle ear.

\section{Methods}

How are tympanograms recorded?

The tympanometer is comprised of three small plastic tubes, which are attached to a metal probe. The three plastic tubes are connected to: 
- a miniature loudspeaker, which emits a pure tone

- a tiny microphone, which picks up the sound of the ear canal

- air pump, which can create either positive or negative pressure within the ear canal.

Results from the tympanometer are placed on a tympanogram which plots the compliance (mobility) of the eardrum on the $\mathrm{Y}$ axis versus the ear pressure of the ear which is measured in daPa (dekapaskals) on the $\mathrm{X}$ axis.

New and advanced middle-ear analysis techniques are developed for testing mechano-acoustic properties of the normal and diseased middle ear in newborns and children. The Interacoustics AT $235 \mathrm{~h}$ is an automatic impedance audiometer well suited for clinics doing screening, as well diagnostic work.

Pediatric audiological assessment protocol emphasize a battery approach to confirmation of hearing impairment in infants. The best protocol for testing newborn include: ABR + OAE + Middle Ear Tests.

The typical algorithm includes physical diagnostic measures:

- Auditory Brainstem Response testing to establish a minimal response level to click

- Acoustic immittance measures to assess middle ear mobility and status
- Otoacoustic Emissions testing to evaluate outher cell function.

Huggard and Lutman (1990) describe the advantages of tympanometry as :

- An easy procedure;

- Comparable data from the different laboratories;

- The measure of immittance has certain advantages, especially combined with other methods;

- The documented results prove objectively the occurrence of change in the middle ear.

- The methodology is noninvasive, quick and easy to perform.

\section{Recommended test protocol for Tympanometry}

- Oto-admittance testing (tympanometry) in the first few mounths of live

- Evidence suggests that tympanometry can be used to help identify middle ear effusion (MEE) at this age, provided a higher frequency probe tone is used.

Using HFT measurements we do middle ear assessment in infants. Tympanograms collected from infants ears are different from those from adults ears.

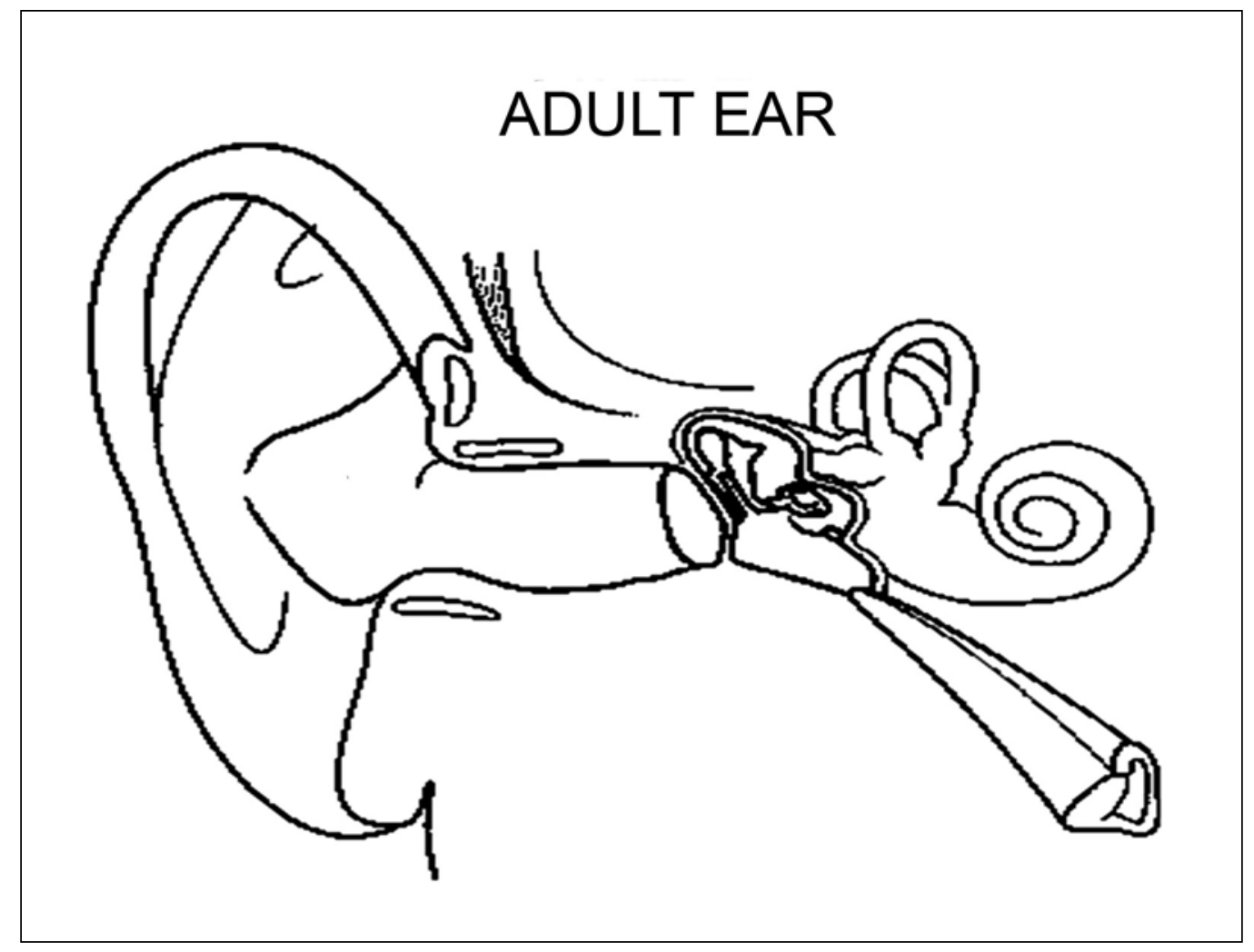




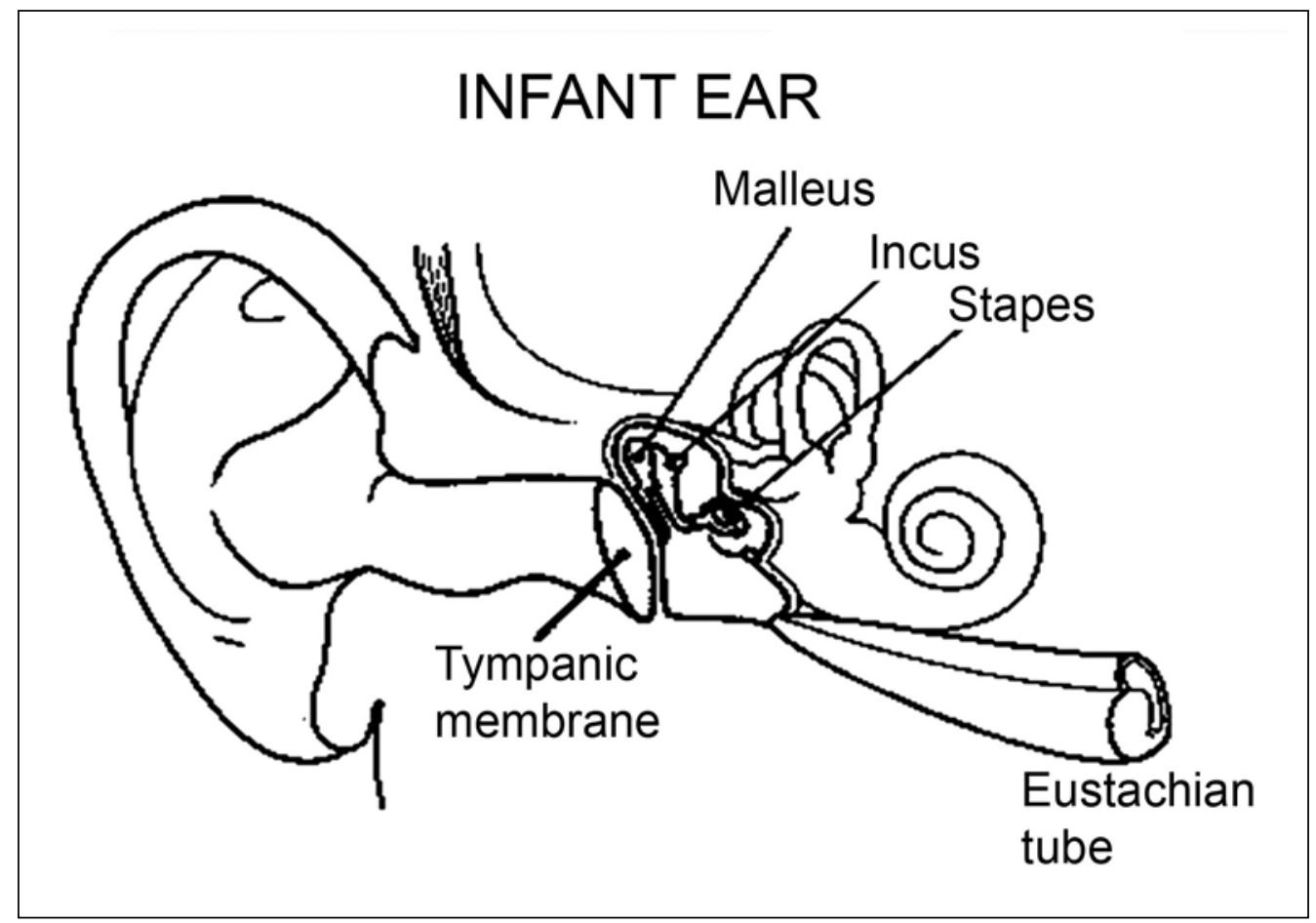

External and middle ear changes after birth that could account for the acoustic alteration includes :

- size increased of the external ear, middle ear cavity and masyoid

- change in orientation of the tympanic membrane

- fussion of the tympanic ring

- decrease in the overall mass of the middle ear (due to changes in the bone density, loss of mesenhyme)

- ightening of the ossicular joints

- closer coupling of the stapes to the ligamentum anulare

- the formation the bony ear canal wall.

The infants middle ear is a mass-dominated system with a lower resonant frequency.

\section{Disscussion}

Tympanograms in pediatric audiology are most commonly used to identify the presence of middle ear fluid i.e. effusion.

It is clearly required immittance measurements use in diagnostic testing when neonatal screening $\mathrm{ABR}$ and $\mathrm{OAE}$ are abnormal.

Best chaice of a tympanometric probe frequency for neonates and infant is $1000 \mathrm{~Hz}$. It is recommended that high-frequency immittance measurements be included in a battery of test to identify any abnormality in an infant's hearing, but they are most effective when they are incorporated along with ABR and OAE results.
Key points from literature:

- Normal $220 \mathrm{~Hz}$ tympanograms may be found in ears with confirmed MEE;

- Abnormal $220 \mathrm{~Hz}$ tympanograms may be found in presumed normal ears;

- Good agreement between higher probe tone frequency tympanometry and MEE presence;

- Good agreement between $1000 \mathrm{~Hz}$ tympanometry and $\mathrm{ABR}$ results.

Neonatal screening programs well particularly appreciate the presence of high probe tone tympanometry, allowing more reliable tympanometric results in neonates.

Using HFT measurements we do middle ear assessment in infants.

Best choice of a tympanometric probe frequency for neonates and infant is $1000 \mathrm{~Hz}$. It is recommended that high-frequency immittance measurements be included in a battery of test to identify any abnormality in an infant's hearing, but they are most effective when they are incorporated along with ABR and OAE results.

\section{Advantages}

- Bellow 4 months of age, a high frequency probe tone must be used because of the different resonance characteristics of the middle ear. Any effects of ear canal wall movement are else minimized by using higher probe tones. 
High frequency tympanometry appear to be valid (i.e. reasonably sensitive and specific) in detecting MEE below 4 months.

Current literature recommendation include the following:

- Bellow 4-7 months of age $1000 \mathrm{~Hz}$ probe tone should be used for detecting middle ear effusion.

- The following $1000 \mathrm{~Hz}$ tympanograms are consider normal single or double-peaked curves.

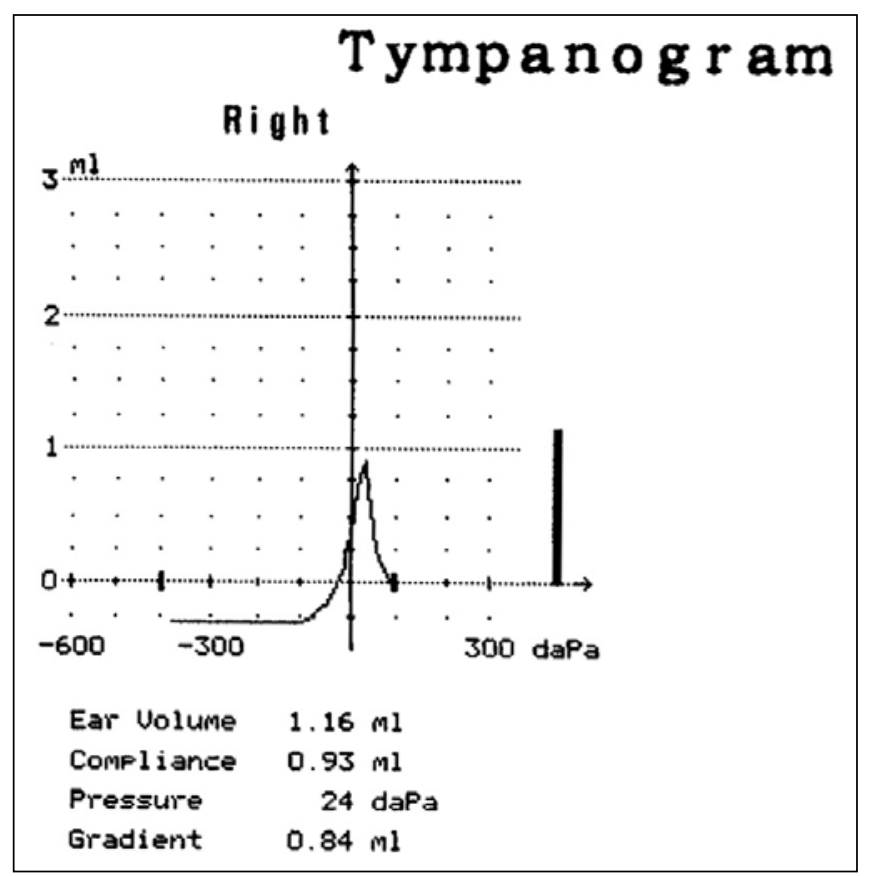

- If normal data are not available for the specific age group, is considered indicative of effusion.

- It is recommended that high-frequency immittance measurements be included in a battery of tests to identify any abnormality in an infants hearing.

- There have been reports of infants with normal 226 $\mathrm{HZ}$ tymps despite confirmed middle ear effusion.
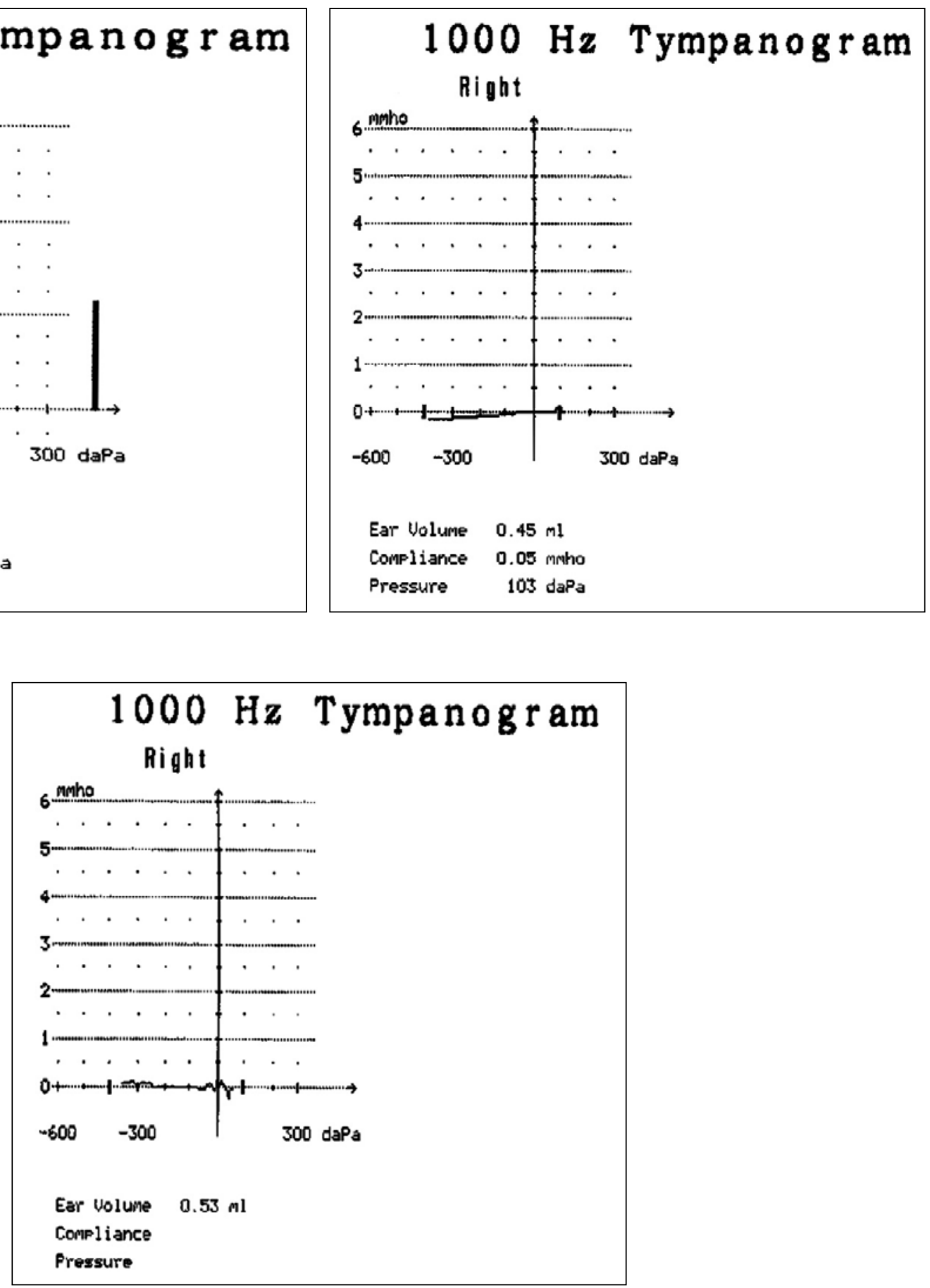


\section{Interpretation}

- Normal pressure from +200 to $-400 \mathrm{daPa}$

- Identify the mean peak

- Measure pressure at peak (middle ear pressure MEP)

Normal if $\mathrm{Y} \geq \mathrm{O}$ and $\mathrm{MEP} \geq-200 \mathrm{daPa}$

Abnormal if $\mathrm{Y} \leq \mathrm{O}$ or $\mathrm{MEP} \leq-200 \mathrm{daPa}$

Positive MEP is more common in this group, with no clinical significance. Multipeaked tympanograms should considered to be normal.

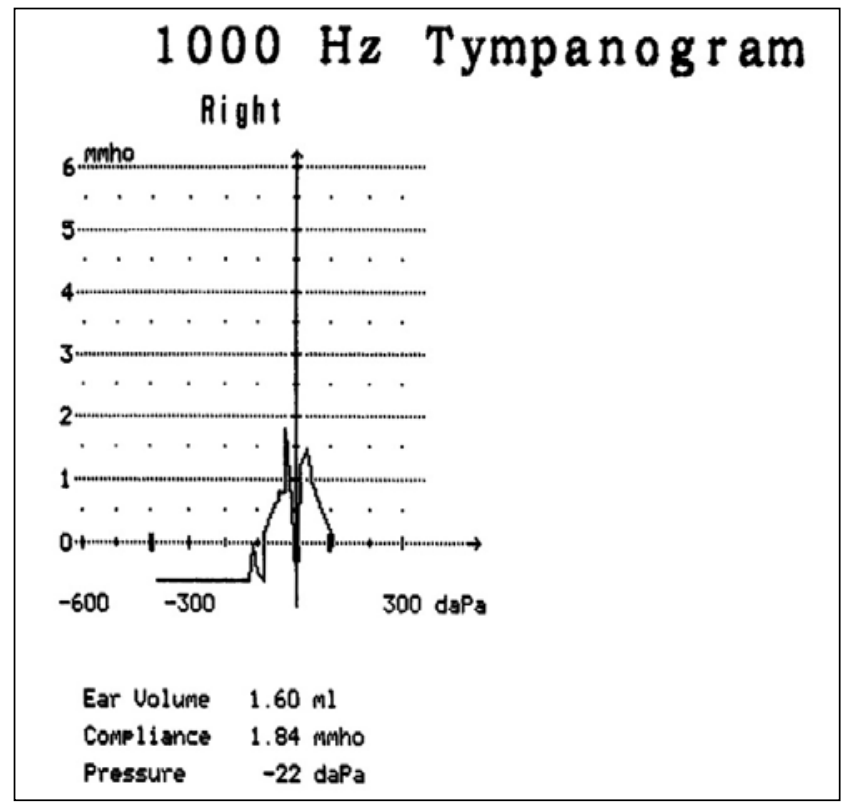

Co

Reference

1. ASHA-American Speech-Language-Haring Association. Guidelines for screening for hearing impairment and middle ear disorders. ASHA, 1990, 32 /Suppl.2 /, 12-24.

2. Baldwin M. Choise of probe tone and classificationof trace patterns in tympanometry undertacen in early infancy. Int. Journal of Audiol., 2006, 45, 417-427

3. Bess F. H., J. W. Hall Screening Children for Auditory Function. Nashvill, Bell Wilkerson Center Press, 1992.

4. Bess F.H., L. E Humes Audiology: the fundamentals. 2 nd. Ed., 1995, Williams \& Wilkins.

5. Block M.G. and T. L. Wiley Owerview and Basic principles of acoustic Immitance in Handbook of Clinical audiology. Ed. J. Katz, 4 ed., Williams \& Wilkins, Baltimor, 1994

6. Campbell K. C. Impedance Audiometry. e Medicine , 20, 2, 2007.

7. Gorga, S. J. Norton Identification on neonatal hearing impairment; infants with hearin loss. Ear Hear., 2000, 2 (5), 488-507.

8. Fowler C. G., J. E Shanks. Tympanometry. In Handbook of clinical audiology, ed. Katz J., R. F. Burkard and L. Medwedsky, 5 th ed., Philadelfia, Lippincott, Williams \& Wilkins, 2002, 175-204

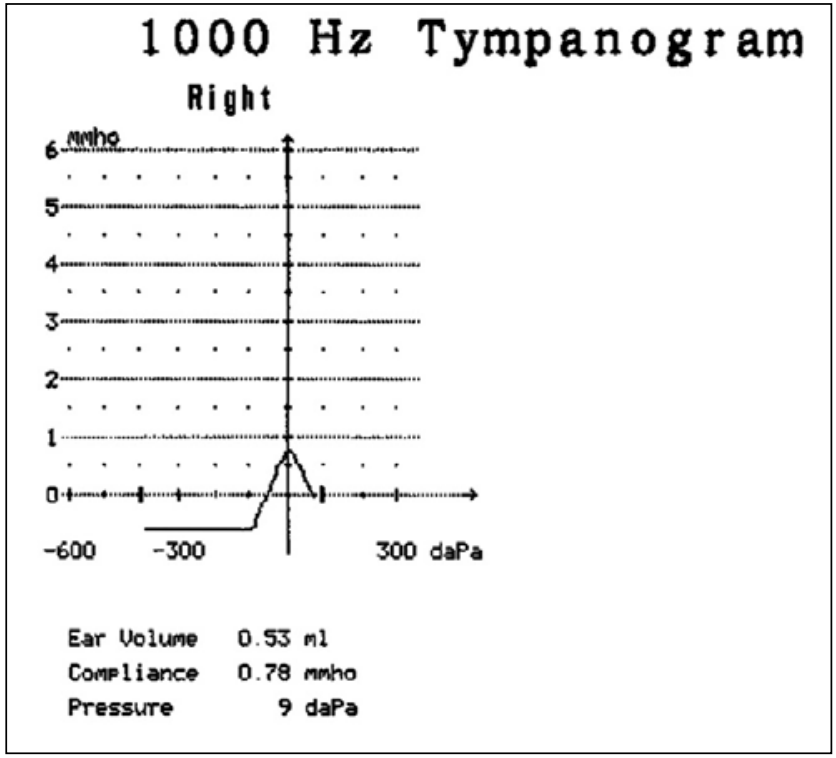

\section{Conclusion}

Tympanometry can assist in diagnosis but should be considered in conjunction with any other results. HFT is more useful than conventional tympanometry in detecting MEE in neonates.

We recommended the use of $1000 \mathrm{~Hz}$ probe tone tympanometry to test babies under 4 months .

9. Grandiri F, M. Lutman The European Consensus Statementon Neonatal Hearing Screening Milano, Italy, 1998

10. Joint Committee on Jnfant Hearing (JCIH) 2000, position statement: principles and guidelines for early hesring detection and intervention programs. Am. J. Audiol., 2000, 9(1), 9-29.

11. Keefe D.H., J.C.Bulen, K.H.Arehart and E.M.Burus Ear canal impedance and reflexion coefficient in human infants and adults. J. Acoust. Soc. Am., 1993, 94:,2617-2638.

12. Margolis R. H., S. Bass-Ringdahl, W. D. Hanks et all. Tympanometry in newborn infants- $1 \mathrm{kHz}$ norms. J. Am. Acad. Audiol., 2003, Sept., 14(7), 383-92.

13. Попова Д, С Върбанова, Й Спиридонова. Високочестотна тимпанометрия. Международен бюлетин по ото-риноларингология, 2007, 1: 18-20.

14. Върбанова С, Приложение на високочестотната тимпанометрия при деца. Практическа педиатрия, 2007, 5: 21-24. 